\title{
La segmentación territorial de la oferta comercial en las áreas turísticas de litoral: una propuesta metodológica
}

\author{
Moisés Simancas Cruz \\ Universidad de La Laguna. Departamento de Geografía e Historia \\ msimancas@ull.es
}

\author{
María Pilar Peñarrubia Zaragoza \\ Universitat de València. Departamento de Geografía \\ mapipeza@uv.es
}

\section{Rafael Temes Cordovez}

Universitat Politècnica de València. Departamento de Urbanismo rtemesc@urb.upv.es

\section{Lucía Palmero del Rosario}

Universidad de La Laguna. Grupo de investigación Reinventur luciapr1993@gmail.com

\section{Ruth de León Rodríguez \\ Universitat Politècnica de València rutdeleo@gmail.com}

\section{Resumen}

La modalidad y la categoría de los alojamientos turísticos se plantean como esenciales en la localización y la tipología de los equipamientos y servicios comerciales de las áreas turísticas de litoral. Esta relación permite identificar patrones espaciales a través de la delimitación de unidades territoriales con cierto grado de homogeneidad respecto a la oferta comercial. El resultado es la segmentación territorial de tales áreas, mediante la definición de zonas de preferencias, necesidades, motivaciones, comportamientos, hábitos, actitudes, expectativas y pautas de consumo de productos y servicios comerciales similares. El objetivo de este trabajo es analizar las potencialidades de dicha segmentación. Para ello se plantea un ejemplo en las áreas turísticas del sur de Tenerife (Canarias, España). Palabras clave: áreas turísticas de litoral; geomarketing; comercio; segmentación territorial 
Resum. La segmentació territorial de l'oferta comercial de les àrees turístiques de litoral: una proposta metodologica

Les característiques dels allotjaments turístics es plantegen com a essencials en la localització i la tipologia dels equipaments i serveis comercials de les àrees turístiques de litoral. Aquesta relació permet identificar patrons espacials a través de la delimitació d'unitats territorials amb cert grau d'homogeneïtat respecte a l'oferta comercial. El resultat és la segmentació territorial d'aquestes àrees, mitjançant la definició de zones de preferències, necessitats, motivacions, comportaments, hàbits, actituds, expectatives i pautes de consum de productes i serveis comercials similars. L'objectiu d'aquest treball és analitzar les potencialitats d'aquesta segmentació. Per fer-ho es planteja un exemple a les Canàries (Espanya).

Paraules clau: àrees turístiques de litoral; geomàrqueting; comerç; segmentació territorial

Résumé. La segmentation territoriale de l'offre commerciale des zones touristiques côtières: une proposition méthodologique

Les caractéristiques de l'hébergement touristique sont considérées comme essentielles pour l'emplacement et la typologie des équipements et des services commerciaux dans les zones touristiques côtières. Cette relation permet d'identifier des schémas spatiaux à travers la délimitation d'unités territoriales avec un certain degré d'homogénéité par rapport à l'offre commerciale. Le résultat est la segmentation territoriale de ces zones, en définissant des zones de préférences, de besoins, de motivations, de comportements, d'habitudes, d'attitudes, d'attentes et de modes de consommation de produits et de services commerciaux similaires. L'objectif de ce travail est d'analyser les potentialités de cette segmentation. Pour cela, nous présentons un exemple concernant les îles Canaries (Espagne).

Mots-clés : zones touristiques côtières ; géomarketing ; commerce ; segmentation territoriale

Abstract. The territorial segmentation of commercial supply in coastal tourist areas: $A$ methodological proposal

The characteristics of tourist accommodation are considered a key aspect of the location and typology of commercial facilities and services in coastal tourist areas. This relationship allows identifying spatial patterns through the delimitation of territorial units with a certain degree of homogeneity with respect to the commercial supply. The result is the territorial segmentation of these areas through the definition of zones of preferences, needs, motivations, behaviors, habits, attitudes, expectations and consumption patterns of similar commercial products and services. The objective of this paper is to analyze the potentialities of this segmentation. To this end, an example is presented of the Canary Islands, Spain.

Keywords: coastal tourism areas; geomarketing; commerce; territorial segmentation 


\section{Sumario}

1. Introducción 4. La segmentación espacial de la oferta

2. Planteamiento del problema: la ausencia de datos y metodología para la definición de patrones de organización espacial de la oferta comercial en áreas turísticas de litoral comercial en Playa del Duque, Playa de Las Américas y Los Cristianos

5. Potencialidades de la segmentación territorial de la oferta comercial en las áreas turísticas de litoral

3. Metodología y fuentes: la segmentación territorial de la oferta comercial en las áreas turísticas de litoral
6. Conclusiones
Referencias bibliográficas

\section{Introducción}

Las compras constituyen una actividad de ocio que los turistas realizan durante sus vacaciones. Butler (1991) diferencia entre cuando el propósito principal de la estancia turística es la compra (turismo de compras) y cuando la compra es una actividad secundaria que se desarrolla durante el transcurso de la misma («ir de compras» o compras de turistas). Por ello, la existencia de tiendas y zonas comerciales constituye una atracción adicional de algunos destinos vacacionales (Moscardo, 2004), que incluso llega a ser una de las motivaciones más importantes de los viajeros (Kim y Littrell, 2001; Reisinger y Turner, 2002; Rosenbaum y Spears, 2009). En este caso, las compras han dejado de ser, en un tiempo relativamente corto, una actividad meramente complementaria para los turistas y se han convertido en una de las principales motivaciones para viajar $y$, por tanto, un factor decisivo en la elección del destino.

Lo anterior supone una oportunidad para que determinados destinos añadan las experiencias de compra como otro valor de su oferta turística (Casais y Sousa, 2019). Esto contribuye a prolongar la estancia en el lugar, representa una experiencia de disfrute y satisfacción (Jansen, 1991; Tosun et al., 2007) y además supone una parte muy importante del gasto turístico realizado en destino (Timothy, 2005).

El contexto territorial donde se ubican los equipamientos y servicios comerciales resulta decisivo en la distribución territorial de la actividad comercial. Esta disposición no es casual en algunas áreas turísticas de litoral, ya que responde a un comportamiento de ubicación causal directamente relacionado con la modalidad (hotelera, apartamento, residencial, etcétera) y la categoría de alojamiento turístico. Por tanto, estos espacios determinan la localización, la tipología e incluso la cualificación de los equipamientos y servicios comerciales en el espacio urbanoturístico (World Tourism Organization, 2014; Peñarrubia et al., 2019). Esto determina la existencia de pautas espaciales de comportamiento diferenciadas entre segmentos de mercado y hace oportuno proceder a su modelización territorial, con el fin de definir patrones de organización espacial.

Desde este punto de vista, la segmentación territorial de la oferta comercial de las áreas turísticas se plantea como una acción oportuna para dicha modeli- 
zación. Se trata de un método y una técnica de zonificación funcional (Rodríguez y Hernández, 2018) susceptible de servir de base territorial para el análisis económico espacial. Se fundamenta en la premisa sociológico-geográfica de que las personas que comparten espacios geográficos cercanos tienden a compartir comportamientos, pautas de consumos y actitudes similares. El resultado es la definición de un conjunto de unidades territoriales homogéneas con cierto grado de similitud en cuanto a la tipología de dicha oferta y, por ende, zonas de preferencias, necesidades, motivaciones, comportamientos, hábitos, actitudes, expectativas y pautas de consumo de productos y servicios similares.

El objetivo principal de este trabajo es poner en relevancia la relación entre la localización y tipología de los comercios y la modalidad y categoría de la oferta de los alojamientos de las áreas turísticas de litoral. Se pretende definir patrones homogéneos de organización espacial de los comercios. Para ello, en la primera parte se evidencian los problemas que existen para la modelización de la oferta comercial. En la segunda se expone la metodología para la definición de unidades territoriales comerciales homogéneas a través de cartografía temática. En la tercera se plantean los patrones de relación entre la ubicación y tipología de comercios y la oferta de alojamiento turístico de tres zonas turísticas del sur de la isla de Tenerife (Canarias, España). En la cuarta se analizan las potencialidades de la segmentación territorial de la oferta comercial en las áreas turísticas de litoral.

\section{Planteamiento del problema: la ausencia de datos y metodología para la definición de patrones de organización espacial de la oferta comercial en áreas turísticas de litoral}

La variable territorial constituye un factor esencial en los procesos de segmentación, e incluso de microsegmentación, de la demanda. Esto convierte el análisis espacial en una cuestión estructural en los procesos de toma de decisiones (Anselin, 1999; Escobar et al., 2015), en general, y de la optimización de la localización de los equipamientos y servicios turísticos, en particular (Castilhos et al., 2014). Sin embargo, las habituales formas de segmentación suelen omitirla. Así, aunque se utilizan conceptos como segmentación geográfica o geosegmentación (Anderson, 2004), el territorio se concibe como un espacio físico y, por tanto, como un mero soporte o entorno en el que se desenvuelve un determinado segmento. Ello determina que la dimensión territorial de los destinos no sea considerada.

Lo mismo sucede con el hecho de que la mayoría de las formas de segmentación omiten que los espacios urbano-turísticos de litoral son sistemas territoriales complejos, heterogéneos y dinámicos, con una especificidad morfológica y funcional. Estas características explican la existencia de unidades territoriales relativamente homogéneas en función de la suposición de elementos y rasgos estructurales. La localización, la modalidad y la categoría de los establecimientos de alojamiento turístico son esenciales en estos procesos de segmentación, e incluso de microsegmentación, no tanto por su incidencia comportamental, 
sino por su capacidad de caracterización de grupos (Alcaide et al., 2012). Ello posibilita la identificación de patrones de organización territorial de la oferta comercial, que son la base para la clasificación espacial de las zonas turísticas dentro de las áreas de litoral, con la consiguiente definición de un esquema territorial que ponga en evidencia y simplifique su diversidad intrínseca. En este punto surgen tres problemas.

El primero se refiere a que gran parte de las investigaciones de los espacios urbano-turísticos de litoral se centran en su consideración como ámbitos territoriales donde pernoctan los turistas, al concentrar los alojamientos turísticos. Estos suelen articular la estructura urbana de las áreas turísticas y definen el espacio público. Sin embargo, en los últimos años, la oferta comercial, que incluye tanto comercios independientes como agrupaciones comerciales ubicadas en centros comerciales, se ha convertido en un «activo» de tales áreas. Así, la investigación en este campo de conocimiento se ha centrado en cuestiones generales (Butler, 1991; Jansen, 1991; Heung y Cheng, 2000; Moscardo, 2004; Timothy, 2005; Pelechá, 2011; Magadán y Rivas, 2014) o específicas relativas a los ingresos generados (World Tourism Organization, 2014), las preferencias y el comportamiento del consumidor (Law y Au, 2000; Lehto et al., 2014; Swanson y Horridge, 2006; Tosun et al., 2007; Wagner, 2007; Park et al., 2009; Meng y Xu, 2012; Sundström et al., 2011) y su grado de satisfacción (Heung y Cheng, 2000; Turner y Reisinger, 2001; Reisinger y Turner, 2002; Wagner, 2007). Sin embargo, el análisis de los equipamientos, infraestructuras y dotaciones de prestación de bienes, ocio y servicios no ha avanzado.

El segundo problema se refiere a la necesidad de disponer de un importante y diverso volumen de información estadística alfanumérica, a microescala y georreferenciada o geocodificada para su adecuada representación cartográfica (Amago, 2000; Peñarrubia, 2018).

Con relación a los datos espaciales, estos deben permitir un conocimiento profundo de las preferencias, los comportamientos, las necesidades, las conductas de compra, las expectativas, los patrones de consumo y las actitudes de los turistas, comparable a lo largo del tiempo y del espacio. El problema radica, entre otras cuestiones, en que, a pesar de la gran cantidad de fuentes estadísticas públicas, estas son insuficientes para conocer el comportamiento del turista en destino (Peñarrubia, 2018). Lo mismo sucede con las derivadas del desarrollo de las tecnologías de la información y comunicación, con un importante impacto desde la perspectiva del consumidor y de la oferta (Ivars et al., 2016). Asimismo, los datos generados y difundidos por las entidades públicas competentes en España presentan importantes limitaciones para mostrar la realidad a escala local del sistema turístico (Peñarrubia y Simancas, 2020), de esta manera, las medias estadísticas a escala municipal no reflejan las diferentes realidades de las distintas áreas turísticas presentes en cada municipio (Rodríguez y Hernández, 2018). Del mismo modo, la información se suele reducir a cifras sobre las entradas y salidas de viajeros, número de pernoctaciones, gasto realizado por los turistas extranjeros, etcétera (Peñarrubia, 2018). A su vez, aunque se dispone de los instrumentos y recursos que hacen posible las condiciones 
óptimas de recogida de datos, aún se adolece de métodos que permitan unificar la información a diferentes escalas territoriales.

Al igual que lo indicado para los datos, resulta habitual la falta de disponibilidad de la correcta localización y delimitación espacial de cada uno de los establecimientos de alojamiento turístico y de los equipamientos comerciales, con la suficiente escala geográfica de desagregación para el desarrollo de un análisis más detallado con valor estadístico y cartográfico. La información alfanumérica existente sobre la oferta alojativa y comercial se limita a los atributos relativos a la dirección postal de cada instalación (calle y número), abstraída a través de la geometría de puntos. Esto es un problema, en la medida en que el microanálisis territorial de la realidad económico-social, a través de instrumentos cartográficos y herramientas de estadística espacial (Chasco, 2003), resulta esencial para la definición de los citados patrones comerciales; así, el concepto de escala adquiere un alto valor. De esta manera, la misma importancia que tienen los datos la tiene prácticamente su representación cartográfica. Para ello resulta necesario disponer de datos espaciales que se puedan procesar mediante estadística espacial, a la vez que representar y visualizar a través de cartografía temática.

El tercer problema se vincula con el hecho de que las áreas turísticas de litoral no cumplen los patrones habituales de los espacios urbanos. Se trata de ámbitos territoriales especializados, con características propias y formas singulares de urbanización (Mullins, 1991) que los distinguen de los espacios urbanos tradicionales. Así, cada espacio urbano-turístico «responde a una práctica urbana singular, funcionalmente y estructuralmente diferenciada de la ciudad convencional» (Antón, 1998: 28), hasta el punto de que suelen presentar «densidades e intensidades de consumo y de ocupación del territorio muy diversificadas, en función del modelo de producto que ofrezca cada ámbito y de la escala a que se establezca el consumo" (Barrado, 2004: 47). Asimismo, como plantean Beritelli et al. (2014) y Chapman y Light (2016), estas áreas se conforman por la agregación de zonas situadas en diferentes etapas de los ciclos de vida según la terminología de los distintos modelos evolutivos descriptivos-predictivos.

La segmentación territorial de las áreas turísticas de litoral se plantea como una solución a estos problemas. Supone la fragmentación o diferenciación de las áreas turísticas de litoral en zonas turísticas homogéneas o pequeños grupos uniformes (subgrupos de consumo) según criterios de concentración y uniformidad territorial. El resultado es la delimitación de un conjunto de unidades territoriales con cierto grado de similitud. Se trata de los denominados «microdestinos» (Papatheodorou, 2006; International Network on Regional Economics, Mobility and Tourism y United Nations World Tourism Organization, 2012), «destinos turísticos locales» (Lew y McKercher, 2006; United Nations World Tourism Organization, 2007), «subdestinos» (Dredge, 1999) o «núcleos turísticos» (ISTAC, 2015).

En el caso del destino de las islas Canarias, lo anterior se ha concretado en la propuesta de microdestinos delimitados por la Unidad Mixta de Metodología e Investigación en Estadística Pública del Instituto Canario de Estadística 
(ISTAC) y de la Universidad de La Laguna. Se trata de zonas o unidades geográficas pequeñas, delimitadas dentro de áreas turísticas de litoral. Estos microdestinos han sido asumidos como unidades territoriales de generación, tratamiento y difusión de datos estadísticos por parte del ISTAC, la entidad pública regional competente en esa materia.

Los criterios utilizados para su definición son los planteados por Hernández et al. (2016) y Rodríguez y Hernández (2018). De esta manera, los microdestinos delimitados en las Canarias responden a uniformidades análogas en cuanto a la modalidad y la categoría de los alojamientos turísticos, dado su papel estructurante de los espacios urbano-turísticos de litoral (Hernández et al., 2016; Lee et al., 2018). El resultado son unidades que se caracterizan por una alta densidad de establecimientos de alojamiento turístico, que presentan indicadores estadísticos homogéneos, continuidad espacial, así como una imagen y una tipología de turismo diferenciadas en cuanto al perfil de los turistas alojados en los mismos. Dada la citada influencia de los alojamientos turísticos sobre la distribución y la tipología de la oferta comercial, en este punto surge una duda: ¿es posible definir patrones homogéneos de organización espacial de esta última en tales microdestinos?

La cuestión por determinar es si esa zonificación con cierto grado de similitud de la oferta alojativa también influye en la organización espacial de la comercial. Se trata de clasificar las áreas turísticas sobre la base de determinadas regularidades y analogías territoriales de los consumidores turísticos. El resultado es la segmentación territorial de las áreas turísticas de litoral en función de la definición de unidades territoriales homogéneas según la oferta comercial. Estas presentan elementos análogos, singulares y específicos en cuanto a preferencias, necesidades, motivaciones, comportamientos, hábitos, actitudes, expectativas y pautas de consumo de productos y servicios comerciales, que satisfacen a determinados tipos de demanda.

\section{Metodología y fuentes: la segmentación territorial de la oferta comercial en las áreas turísticas de litoral}

La segmentación territorial de la oferta comercial en los tres microdestinos seleccionados - Bahía del Duque (municipio de Adeje) y Los Cristianos y Playa de Las Américas (municipio de Arona) - se ha planteado de lo particular a lo general, de lo simple a lo compuesto, de los hechos individuales a las generalizaciones. Para ello, las técnicas y metodologías de geomarketing se muestran como adecuadas. Amago (2000) lo plantea como la visualización del mercado, clientes y atributos alfanuméricos en un mapa temático y en otros tipos de mapas para poder apreciar mejor las relaciones, tendencias y oportunidades de negocio en un área geográfica. Latour y Le Floch (2001) lo definen como un sistema integrado por datos, programas informáticos de tratamiento, métodos estadísticos y representaciones gráficas, destinados a producir una información útil para la toma de decisiones, a través de instrumentos que combinan la cartografía digital, gráficos y tablas. Chasco (2003) lo concibe como un conjunto de 
técnicas que permiten analizar la realidad económico-social desde un punto de vista geográfico, a través de instrumentos cartográficos y herramientas de la estadística espacial. Alcaide et al. (2012) lo plantean como el área del marketing orientada al conocimiento global del cliente, sus necesidades y comportamientos dentro de un entorno geográfico determinado, que nos ayuda a tener una visión más completa del mismo y a identificar sus necesidades. Harris (2003) lo referencia al análisis de los datos socioeconómicos y del comportamiento de la población, con el fin de investigar los patrones geográficos que estructuran y son estructurados por las características de los asentamientos. Su capacidad como técnica de análisis espacial está demostrada en la aplicación de procesos de toma de decisiones de negocio basadas en variables espaciales (Grimmeau y Roelants, 1995; García, 1996; Galacho, 1999; Latour y Le Floch, 2001; Moreno, 2001; Cliquet, 2006; Corbera et al., 2002; Douard y Heitz, 2004; Bocalandro y Krauthamer, 2007; Alcaide et al., 2012; Moreno, 2012; Castilhos et al., 2014; Montejano y Cruz, 2018), la planificación comercial (García, 1996; Moreno, 2002; Chasco, 2003; Moreno y Prieto, 2004; Chasco et al., 2009; Baviera et al., 2016; Rodríguez et al., 2016), el conocimiento del consumidor (Alcaide et al., 2012; Allo, 2014), la geolocalización y la atracción comercial (Doyle, 2001; Vallejo y Márquez, 2006; Chacon, 2017), la logística y el marketing (Amago, 2000) y el análisis de los patrones de comportamiento de los turistas (Oppermann, 1997; Chancellor y Cole, 2008; Ferreira, 2011; Beltrán, 2014; Jin et al., 2017; Peñarrubia, 2018; Peñarrubia et al., 2019; Sousa et al., 2019).

El geomarketing incluye una serie de procesos fundamentales como la localización y gestión de la información estadística de carácter territorial, el manejo de un software propio de Sistema de Información Geográfica (SIG), el dominio de técnicas estadísticas y econometría espacial (modelos de localización, modelos de interacción espacial, regresión espacial) y el uso de las herramientas propias del marketing estratégico (figura 1).

En cuanto a la información utilizada, se procedió a la construcción de dos capas temáticas: la de la oferta de establecimientos de alojamiento turístico y la de la comercial. En ambos casos se partió de fuentes de información tabuladas en las que se identificó una columna clave o de referencia para poder realizar el enlace de varias fuentes alfanuméricas y su posterior posicionamiento espa-

Figura 1. Sistema de geomarketing

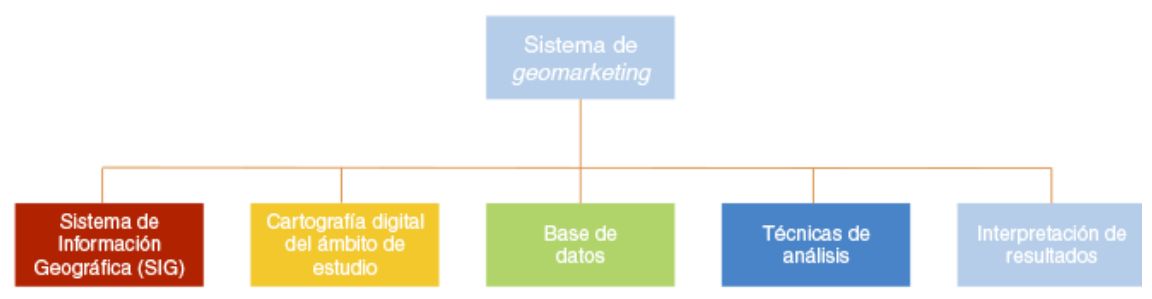

Fuente: Peñarrubia (2018). 
Figura 2. Procedimiento metodológico secuencial de delimitación de parcelas ocupadas por establecimientos alojativos turísticos

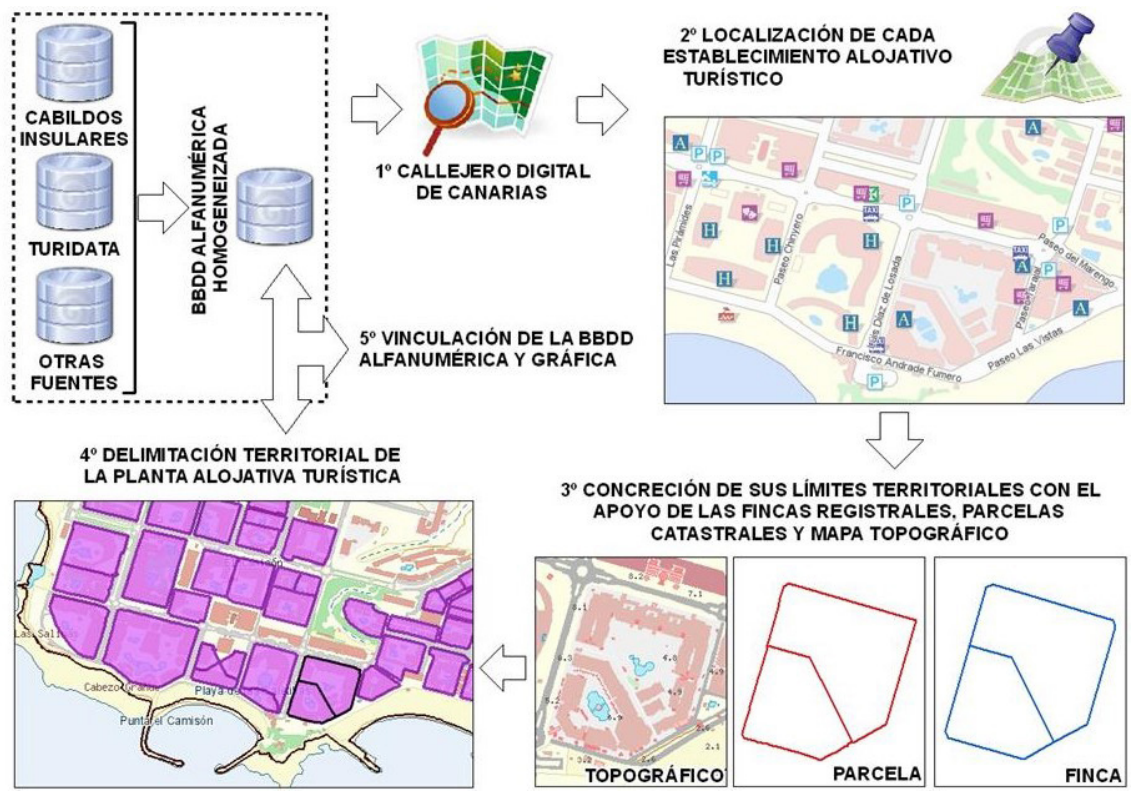

Fuente: elaboración propia.

cial. El uso de un SIG ha resultado una herramienta esencial. En este sentido, Moreno (2001) destaca que la principal contribución a la eclosión popular del geomarketing ha sido la alta tecnología geográfico-informática que representan los SIG.

La elaboración de la primera capa temática, la relativa a la oferta de alojamiento turístico, siguió el proceso secuencial planteado en la figura 2. Los atributos vía y número de la dirección postal de cada alojamiento turístico aportados como geometría de puntos por el callejero digital de las Canarias, generado por la empresa pública Cartográfica de Canarias (Grafcan), se utilizaron como referencia para determinar la localización concreta de los establecimientos de alojamiento en un área turística. Dado que esta solo posee una única dimensión y carece de una superficie asociada, fue preciso obtener una segunda dimensión a través de la geometría poligonal. Esta permitió obtener la verdadera entidad territorial para cada establecimiento de alojamiento turístico. Para ello, el trazado de esta delimitación espacial exigió tener fuentes de apoyo, con el fin de obtener un perímetro lo más ajustado posible a la realidad. La información alfanumérica y las bases gráficas del registro de la propiedad y del catastro constituyeron tales fuentes.

Las bases gráficas del registro y del catastro son accesibles mediante un servicio Web Map Service (WMS). Por su parte, la cartografía en formato 
vectorial Shapefile del catastro es de libre acceso a través de la Sede Electrónica del Catastro (SEC). Si bien ambas bases gráficas, bajo el modelo de datos vectorial, aportan información sobre la propiedad inmobiliaria, son independientes (Delgado, 2010; García et al., 2013). Así, presentan características técnicas distintas: mientras que las parcelas catastrales - subparcelas y construcciones contenidas en las mismas- se basan en la delimitación física según sus contornos y la apariencia de pertenencia a un mismo poseedor (Delgado, 2010), en las del registro de la propiedad, el dibujo se basa en la delimitación de la finca matriz, con la presencia de una geometría poligonal y dejando la subdivisión horizontal de la propiedad fuera de la delimitación cartográfica. El resultado es que el trazado de la parcela catastral y la finca registral puede no coincidir. Ello obligó a su coordinación, con el fin de trabajar con una única representación cartográfica georreferenciada con una superficie registral y catastral coordinada, con la asunción de errores derivados tanto de la propia delimitación de la parcela catastral como de la interpretación de la descripción literaria aportada al registro, su ambigüedad e inexactitud. La corrección de estos desajustes y discordancias se hizo con la ortofotografía y, sobre todo, el mapa topográfico de las Canarias a escala 1:1.000. Si bien este procedimiento ha supuesto que la parcela delimitada para cada alojamiento turístico no se corresponda exactamente con la fuente oficial y, por tanto, con su superficie y límites, con la pérdida de su correspondiente valor jurídico, sin embargo, se ha logrado una valiosa precisión. El resultado es la generación de una novedosa base de datos gráfica con la entidad territorial de cada establecimiento de alojamiento turístico (figura 3).

Los datos abiertos consultables a través de los servicios disponibles, esto es, la descarga de datos, conexión con servicios WMS, a través de la Infraestructuras de Datos Espaciales (IDE), servicios estadísticos (Instituto Estadístico de Canarias y servicios estadísticos del Cabildo Insular de Tenerife) y la Sede Electrónica del Catastro, constituyen la información relativa a cada establecimiento de alojamiento turístico identificada y, por tanto, las parcelas delimitadas espacialmente. La información catastral fue la relativa a la referencia catastral, la dirección postal (localización), la superficie de suelo, la superficie construida, el coeficiente de participación (en \%), el uso, el año de la construcción del local principal, así como el tipo de finca (parcela con un único inmueble o parcela con varios inmuebles división horizontal), mientras que la asociación se realizó de forma directa, mediante la tabla de atributos de la cartografía en formato vectorial Shapefile, así como un enlace con las .Cat de la Sede Electrónica del Catastro, su transformación en atributos de tablas .shp mediante el procedimiento que ofrece la propia sede. Por su parte, la información del registro de la propiedad se almacenó de forma descriptiva, igual que las divisiones verticales y horizontales: mientras que la identificación registral (validada, provisional, pendiente o sin especificar), de libre acceso, solo se pudo gestionar vía web, el número de divisiones horizontales aportó valores numéricos.

La información relativa a la oferta de alojamiento turístico (número de plazas, categoría, modalidad, etcétera) asociable a cada parcela es la aportada por 
Figura 3. Parcelario resultante de los establecimientos de alojamiento turístico en los microdestinos de Playa de Las Américas y Los Cristianos (Arona, Tenerife)

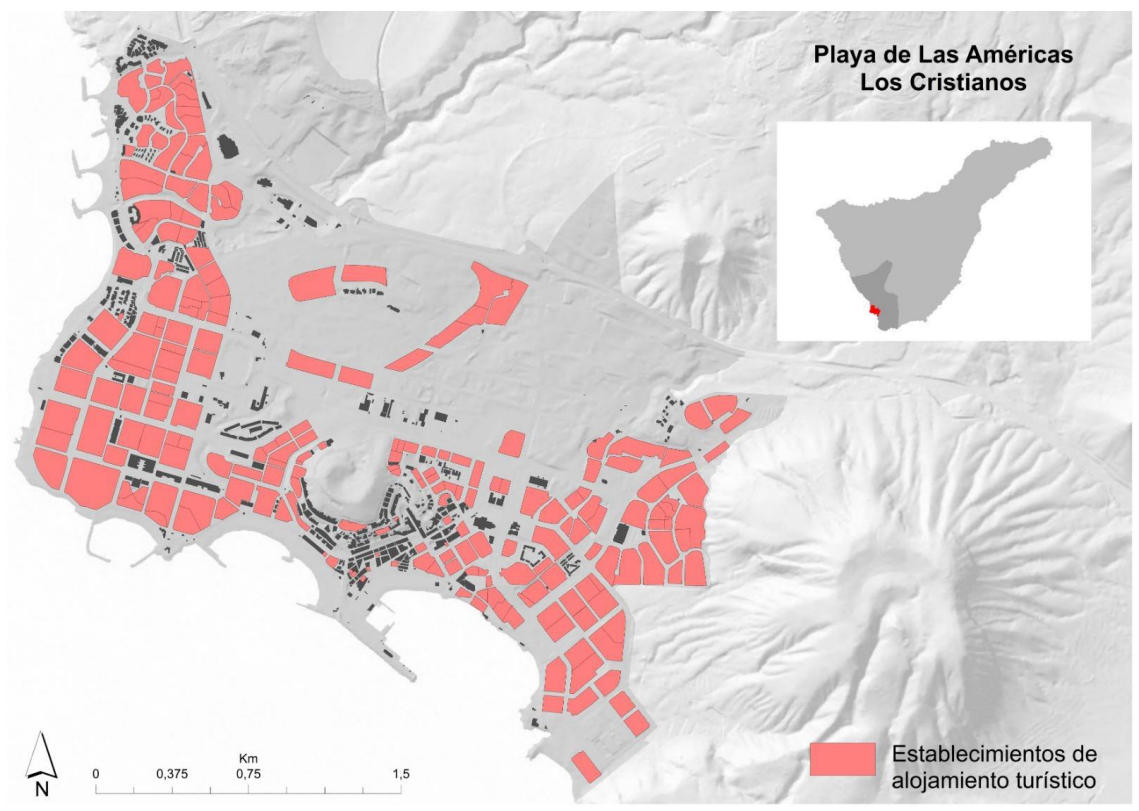

Fuente: elaboración propia.

el Directorio de Alojamientos Turísticos Colectivos de las Canarias (Alojatur) debidamente georreferenciada. Esta se completó con la información aportada por las operaciones estadísticas de demanda, a través de las cuales se detectan ofertas no registradas oficialmente o cambios de categorías respecto a la oferta oficializada. El resultado es la cartografía de las figuras 4 y 5.

Finalmente, la base de datos alfanumérica Alojatur quedó vinculada a la base gráfica previamente construida (figura 6). La conexión se realizó mediante el campo de atributo común de la referencia catastral.

La capa temática de la oferta comercial se elaboró con el Censo de Comercios y Servicios de la isla de Tenerife, aportado por la Unidad del Banco de Datos y Centro de Documentación del Cabildo de Tenerife. Además de los comercios, las actividades referentes a hostelería y restauración, servicios, alimentación, y medicina y salud también se han elegido para su georreferenciación. Su inclusión en el estudio se justifica por el hecho de considerarlas como actividades complementarias a la oferta comercial, entendidas como negocios que pueden formar parte de la experiencia global del turismo de compras. El proceso de geocodificación empleado ha sido el directo, es decir, ha sido posible asignar coordenadas geográficas a partir de un listado de direcciones en formato alfanumérico (tipo y nombre de la calle, número, ciudad, provincia y país). Para el volumen de puntos a localizar 
Figura 4. Representación cartográfica de la modalidad de los establecimientos de alojamiento turístico en los microdestinos de Bahía del Duque, Playa de Las Américas y Los Cristianos (Arona, Tenerife)
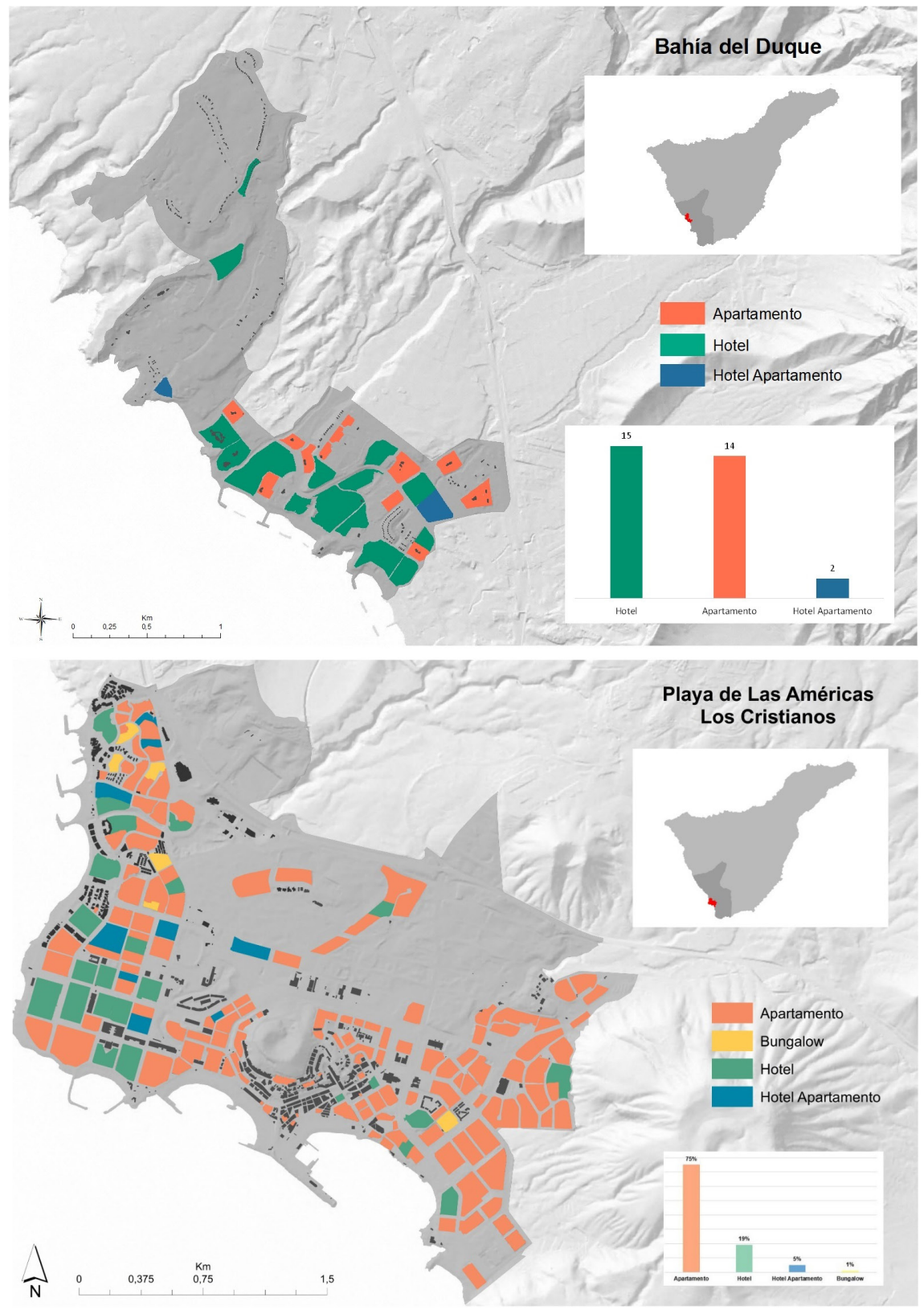

Fuente: elaboración propia. 
Figura 5. Representación cartográfica de la modalidad de los establecimientos de alojamiento turístico en los microdestinos de Bahía del Duque, Playa de Las Américas y Los Cristianos

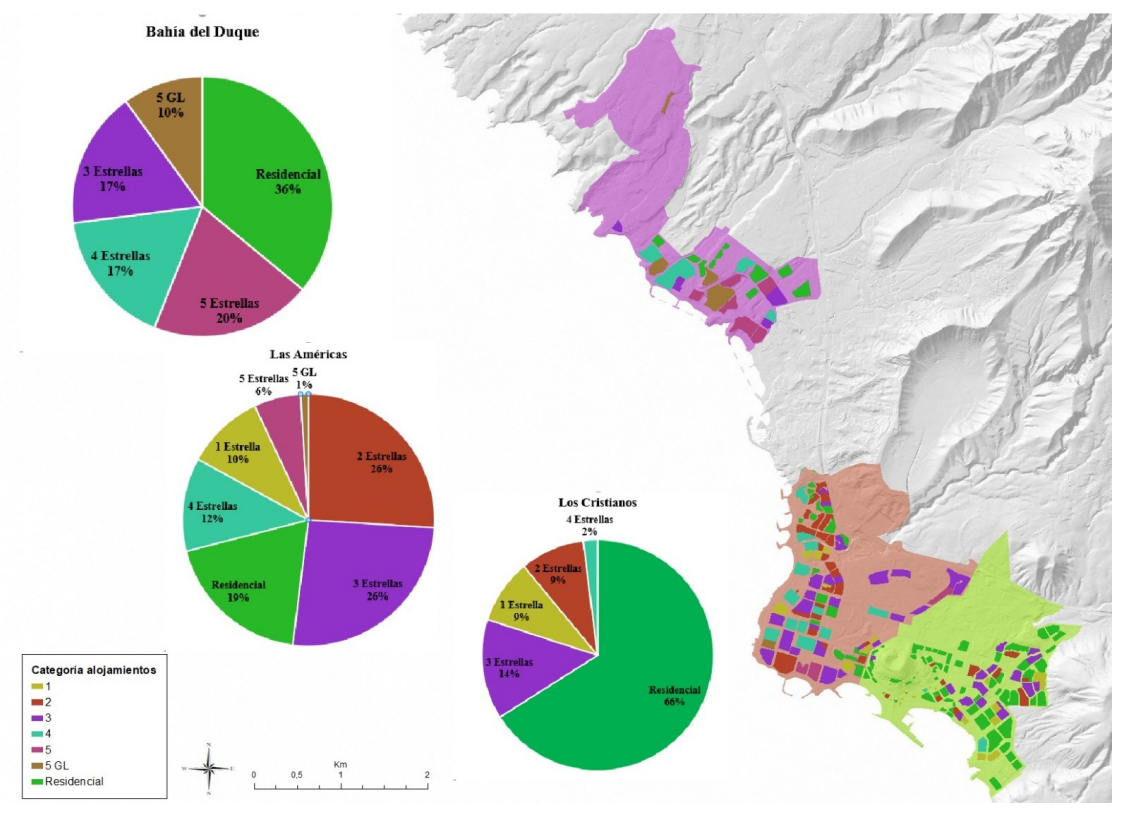

Fuente: elaboración propia.

(1.956), ha sido posible logarlo con calidad suficiente mediante el uso de la API de Cartociudad. Si bien la carga de información está limitada a 100 etiquetas de forma simultánea, se realizó el proceso 20 veces hasta obtener la totalidad de puntos referenciados. La calidad de información de partida se demostró suficientemente alta, ya que la identificación sobre la cartografía fue superior al $95 \%$. El resto de los puntos se lograron posicionar de manera manual (figura 7).

La combinación de las capas temáticas de alojamientos turísticos y de los equipamientos y servicios comerciales generó un mapa de síntesis. Este contiene la información necesaria para la optimización de la localización de estos últimos en relación con las características (modalidad y categoría) de la oferta de alojamiento turístico (figuras 8 y 9).

\section{La segmentación espacial de la oferta comercial en Playa del Duque, Playa de Las Américas y Los Cristianos}

Los tres microdestinos seleccionados presentan situaciones diferentes en función de la modalidad y la tipología de los alojamientos turísticos: mientras que en los de Los Cristianos predomina la oferta residencial y en Las Américas fundamentalmente los apartamentos turísticos, en Bahía del Duque sobresale 
Figura 6. Información alfanumérica vinculada a las parcelas de los establecimientos de alojamiento turístico en los microdestinos de Los Cristianos y Playa de Las Américas
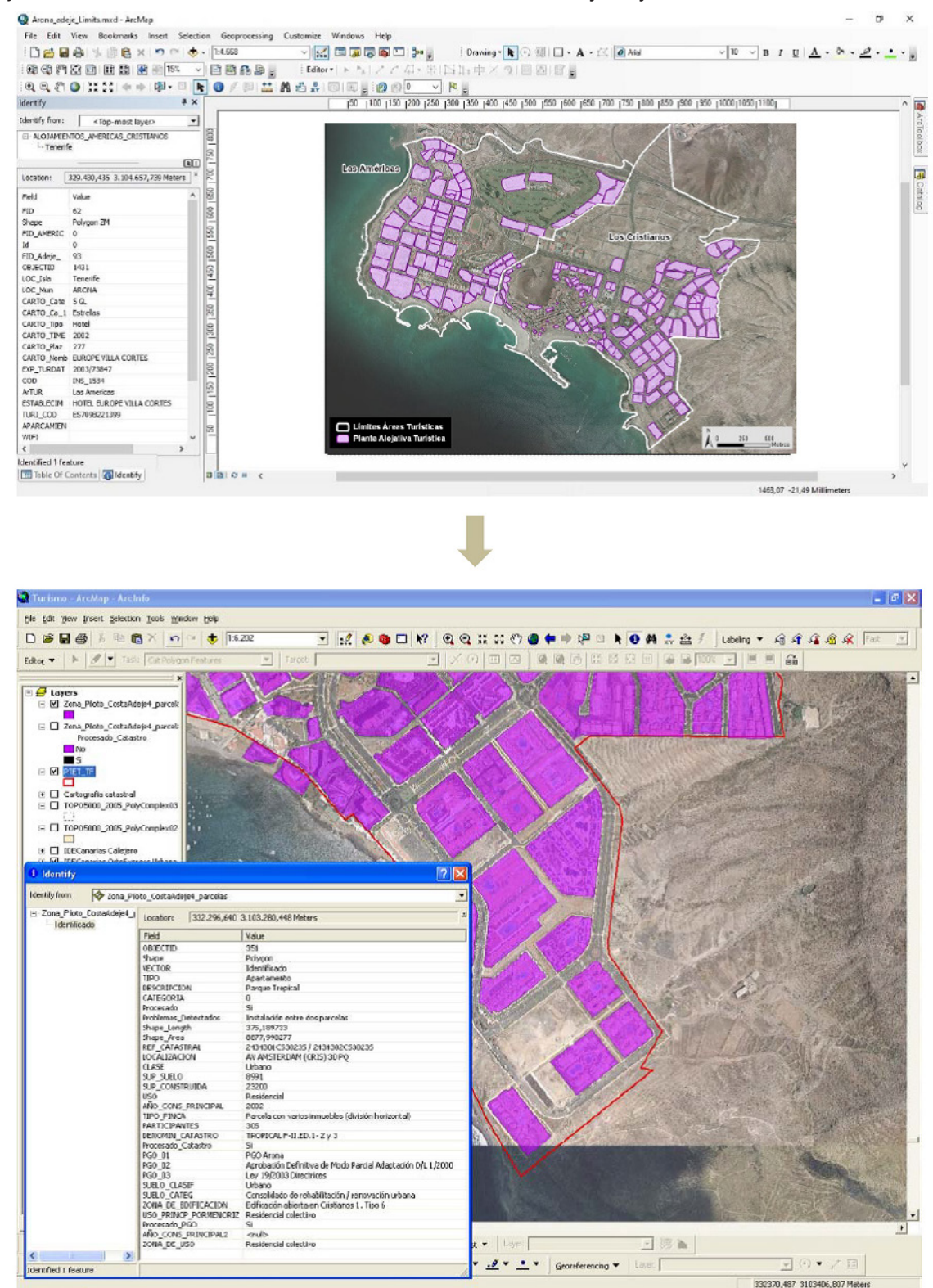

Fuente: Alojatur. Elaboración propia. 
Figura 7. Representación cartográfica de la ubicación de los comercios en los microdestinos de Bahía del Duque, Los Cristianos y Playa de Las Américas
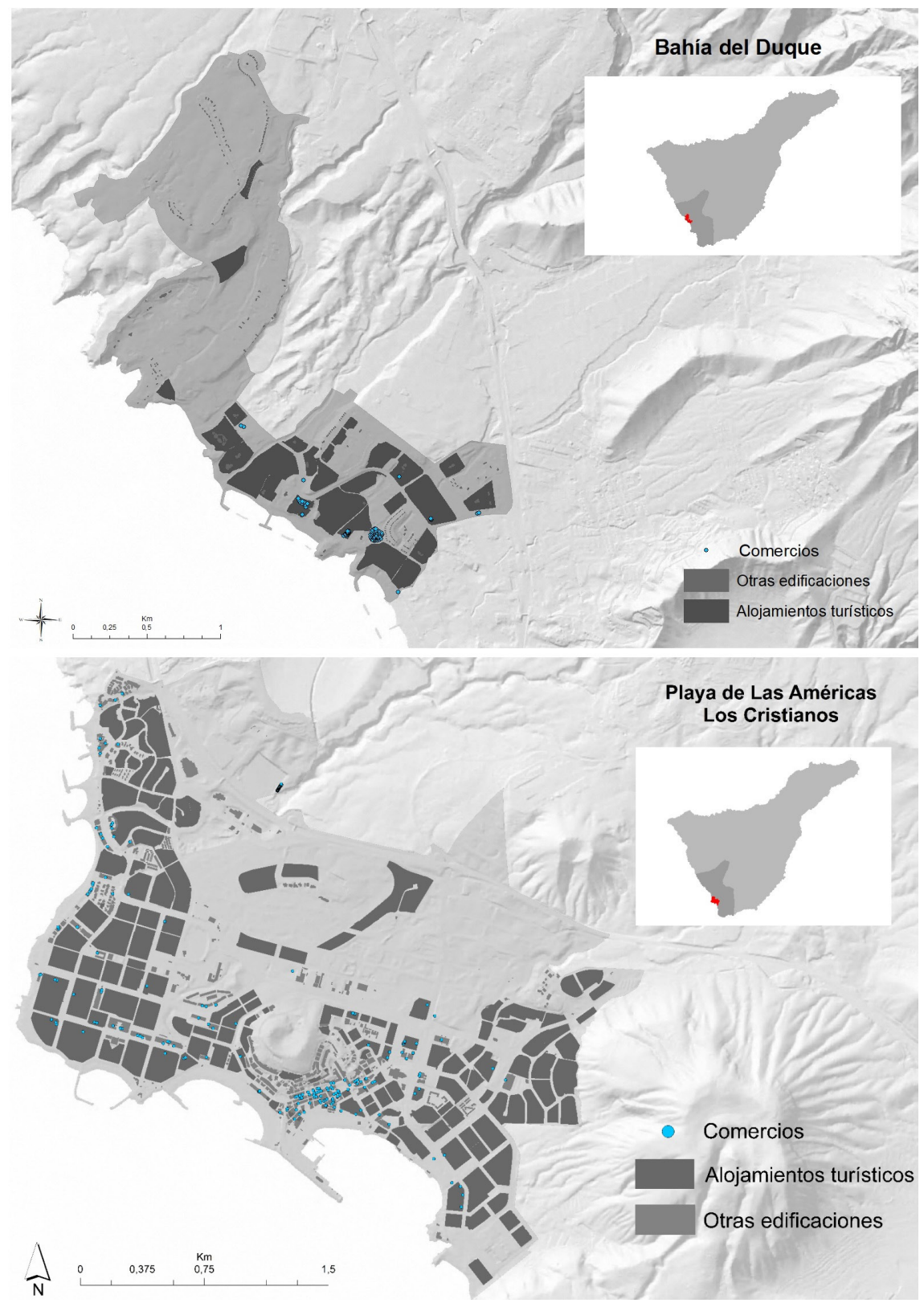

Fuente: Tenerifedata. Elaboración propia (2019). 
Figura 8. Representación cartográfica de la localización de la tipología de los comercios en relación con la categoría de los alojamientos turísticos en los microdestinos de Bahía del Duque, Los Cristianos y Playa de Las Américas
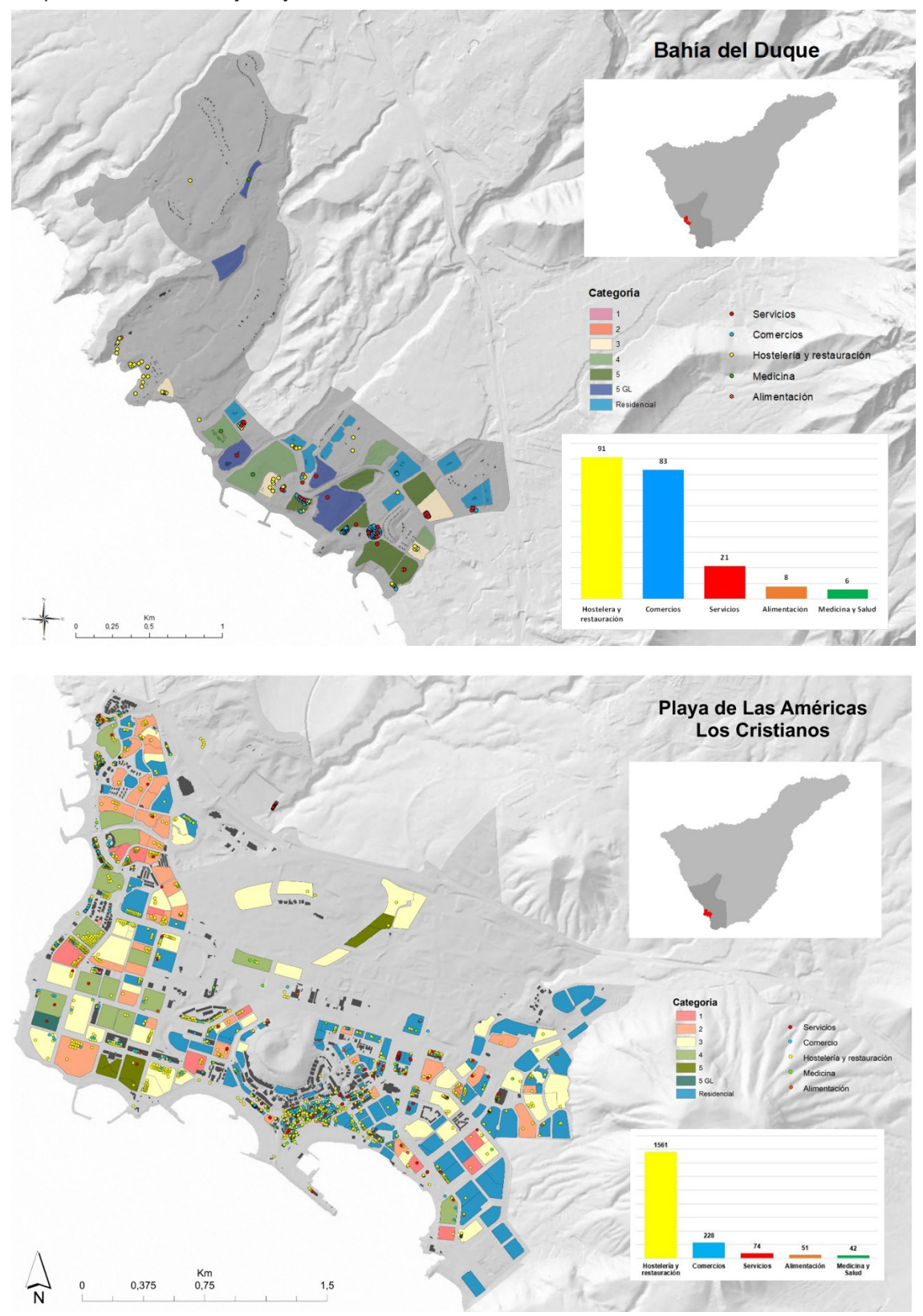

Fuente: Tenerifedata. Elaboración propia (2019). 
Figura 9. Representación cartográfica de la localización de los comercios en relación con la tipología de los alojamientos turísticos en los microdestinos de Bahía del Duque, Los Cristianos y Playa de Las Américas

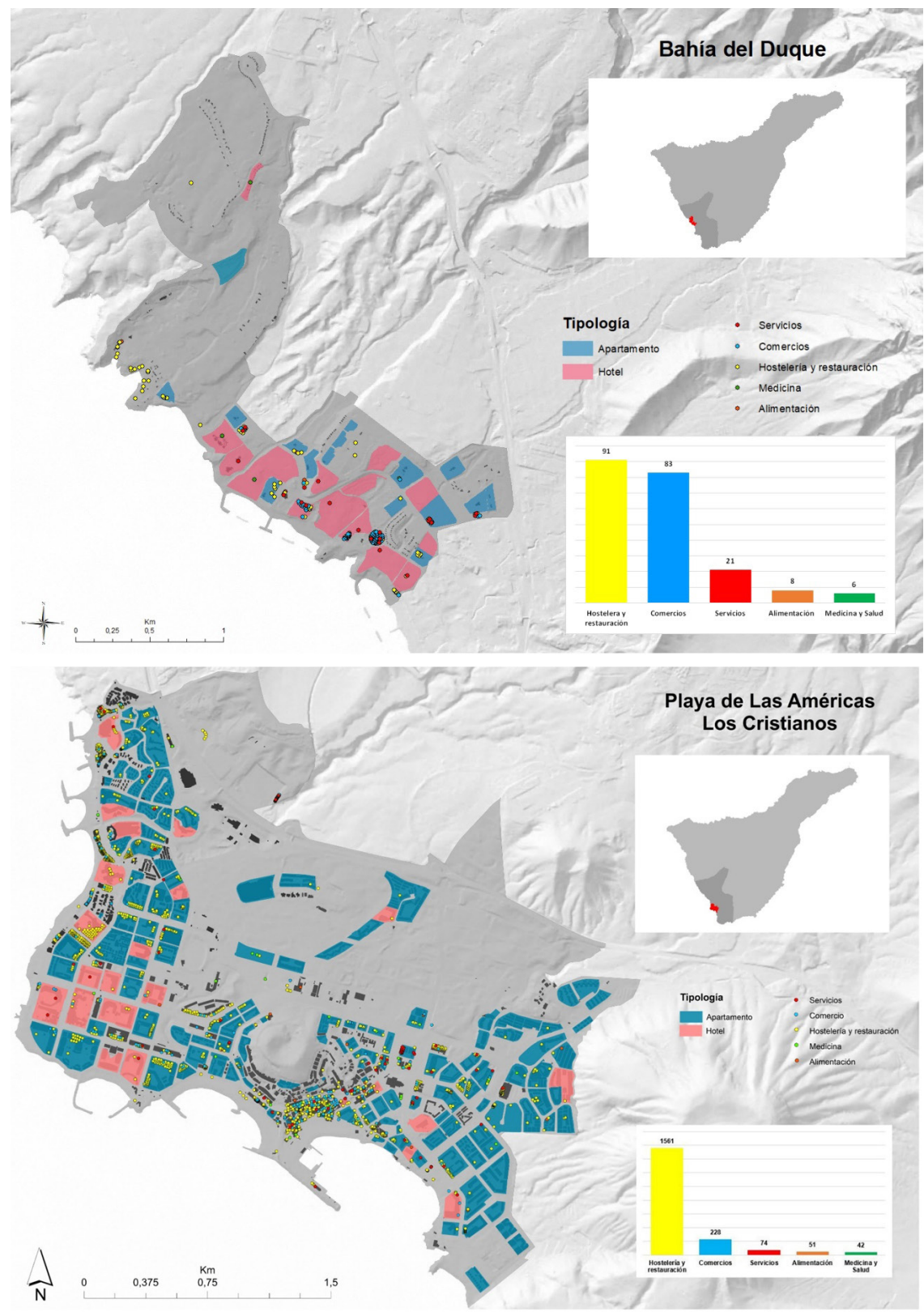

Fuente: Tenerifedata. Elaboración propia (2019) 
la hotelera superior a cuatro estrellas. Esta diferencia de modelo alojativo - $y$, por ende, de turistas - se traduce en que las tarifas medias por habitación (ADR) y los ingresos por habitación disponibles (RevPar) son notablemente distintos (tabla 1). Esto es consecuencia de las estrategias que guiaron su desarrollo territorial.

Los Cristianos (Arona) es un núcleo turístico que parte de un asentamiento residencial original que se formó en torno a la playa del mismo nombre. $\mathrm{Su}$ crecimiento y su consolidación se produjeron mediante dos procesos: por un lado, la sustitución de las antiguas viviendas por edificaciones residenciales colectivas; $y$, por otro, la ocupación de parcelas fundamentales por establecimientos extrahoteleros (apartamentos).

Las Américas (Arona) es un núcleo turístico sin un sustrato residencial previo, con un desarrollo del espacio urbano-turístico ex novo. Presenta una estructura urbana de gran compacidad, con una variedad de tipologías edificatorias y una interesante distribución, de gran relevancia para la organización del comercio: si bien se produce un predominio de los establecimientos extrahoteleros (el 75\%), el 87\% de los hoteles son de una categoría de cuatro o más estrellas. Se trata de un microdestino cuyo desarrollo inicial respondió a estrategias de mass customization, con el consiguiente predominio de los paquetes baratos y estandarizados (homogéneos y poco diferenciados), que eran producidos con la eficiencia de una producción y especialización «en masas", destinados a un cliente de clase media, poco exigente, y centrados en el producto «de sol y playa».

La estructura alojativa del microdestino Bahía del Duque (Adeje) es resultado de la materialización territorial de lo previsto en el Decreto 10/2001, de 22 de enero, por el que se regulan los estándares turísticos y se definen una serie de parámetros físicos mínimos de los diferentes elementos estructurales del alojamiento turístico. Esto generó un modelo edificatorio de "hoteles horizontales», de categoría de cinco estrellas, que se ubican en grandes parcelas, a modo de «resort caribeño». Se trató de una estrategia de upgrading, al plantearse como un proceso ascendente en la cadena de valor a través del alejamiento de las actividades con bajas barreras de entrada. Esta limitación exclusiva a la «gama alta» de los alojamientos turísticos y, por ende, a un perfil deseado de los turistas (clientes) supuso un cauce de cualificación de la oferta de alojamiento turístico (tabla 1).

Por su parte, la hostelería y la restauración engloban el 79\% de la oferta comercial, seguidas de los comercios (13\%) (gráfico 1). Esta distribución es heterogénea desde el punto de vista cuantitativo en los tres microdestinos seleccionados: Los Cristianos acapara el mayor número de comercios (el 60,5\%), seguido de Playa de Las Américas (el 33,1\%) y Bahía del Duque (6,4\%).

A pesar de la diferente mixtura y tipos de concentración de equipamientos y servicios comerciales, se puede apreciar una cierta segmentación territorial (figura 10). Las unidades territoriales homogéneas comerciales resultantes evidencian isomorfismos simplificados según las pautas repetitivas y regularidades de las relaciones entre la oferta comercial y la alojativa (figura 10). Estas 
Tabla 1. Principales indicadores turísticos de los microdestinos de Playa del Duque, Playa de Las Américas y Los Cristianos (2019)

\begin{tabular}{|c|c|c|c|c|c|}
\hline & & & $\begin{array}{l}\text { Playa del } \\
\text { Duque }\end{array}$ & $\begin{array}{l}\text { Playa de } \\
\text { Las Américas }\end{array}$ & Los Cristianos \\
\hline Superficie (en ha) & & & 398,39 & 387,08 & 265,47 \\
\hline \multirow{15}{*}{$\begin{array}{l}\text { Número de establecimientos } \\
\text { de alojamientos }{ }^{\star}\end{array}$} & \multirow[t]{7}{*}{ Hotelero } & 1 estrella & - & - & \\
\hline & & 2 estrellas & - & - & 1 \\
\hline & & 3 estrellas & - & 3 & 2 \\
\hline & & 4 estrellas & 5 & 13 & 2 \\
\hline & & 5 estrellas & 6 & 6 & - \\
\hline & & 5 estrellas GL & 4 & 1 & - \\
\hline & & Residencial & 11 & 1 & - \\
\hline & \multirow[t]{7}{*}{ Extrahotelero } & 1 estrella & - & 11 & 11 \\
\hline & & 2 estrellas & - & 29 & 10 \\
\hline & & 3 estrellas & 5 & 27 & 15 \\
\hline & & 4 estrellas & - & 1 & - \\
\hline & & 5 estrellas & - & - & - \\
\hline & & 5 estrellas GL & - & - & - \\
\hline & & Residencial & - & 20 & 79 \\
\hline & \multicolumn{2}{|l|}{ Total } & 31 & 112 & 120 \\
\hline \multicolumn{3}{|l|}{ Plazas ofertadas* } & 12.081 & 28.417 & 11.893 \\
\hline \multicolumn{3}{|l|}{ Pernoctaciones ${ }^{\star \star}$} & 3.540 .258 & 7.351 .669 & 2.592 .615 \\
\hline \multicolumn{3}{|l|}{ Estancias medias ${ }^{\star \star}$} & 7,44 & 7,67 & 7,89 \\
\hline \multicolumn{3}{|c|}{ Tasa de ocupación por habitaciones-apartamentos ${ }^{\star \star}$} & 83,52 & 82,00 & 76,30 \\
\hline \multicolumn{3}{|c|}{ Tasa de ocupación por plazas ${ }^{\star \star}$} & 80,29 & 70,88 & 59,72 \\
\hline \multicolumn{3}{|c|}{ Tarifa media por habitación mensual (ADR) (en euros) ${ }^{\star \star}$} & 143,03 & 85,84 & 84,28 \\
\hline \multicolumn{3}{|c|}{ Ingresos por habitación disponible (RevPAR) (en euros) ${ }^{\star \star}$} & 119,14 & 70,20 & 64,13 \\
\hline \multicolumn{3}{|l|}{ Ingresos totales (en euros) ${ }^{\star \star}$} & 244.104.174,4 & $288.211 .149,3$ & $99.705 .127,8$ \\
\hline
\end{tabular}

Fuente: * elaboración propia a partir de TURIDATA; ** ISTAC.

se comportan a modo de "categoremas», ya que posibilitan la identificación de los diferentes patrones según la función de pertenencia u homogeneidad respecto a preferencias, comportamientos, necesidades, conductas de compra, expectativas, patrones y actitudes de consumo.

Cada unidad territorial presenta su propia aptitud, entendida como la medida en que responde a los requisitos de localización de la actividad comercial o, lo que es lo mismo, una vocación propia y específica para un tipo concreto de comercios. Así, podemos apreciar, al menos, tres patrones de funcionamiento de la oferta comercial claramente vinculados con las características de los alojamientos turísticos.

Los equipamientos y servicios comerciales de Los Cristianos y Playa de Las Américas se localizan fundamentalmente en las plantas bajas de los establecimientos de alojamientos turísticos - en especial en las de ordenación por alineaciones de calle que forman manzanas cerradas-, en edificios específicos 
Gráfico 1. Distribución territorial de la oferta comercial en los microdestinos de Playa del Duque, Playa de Las Américas y Los Cristianos

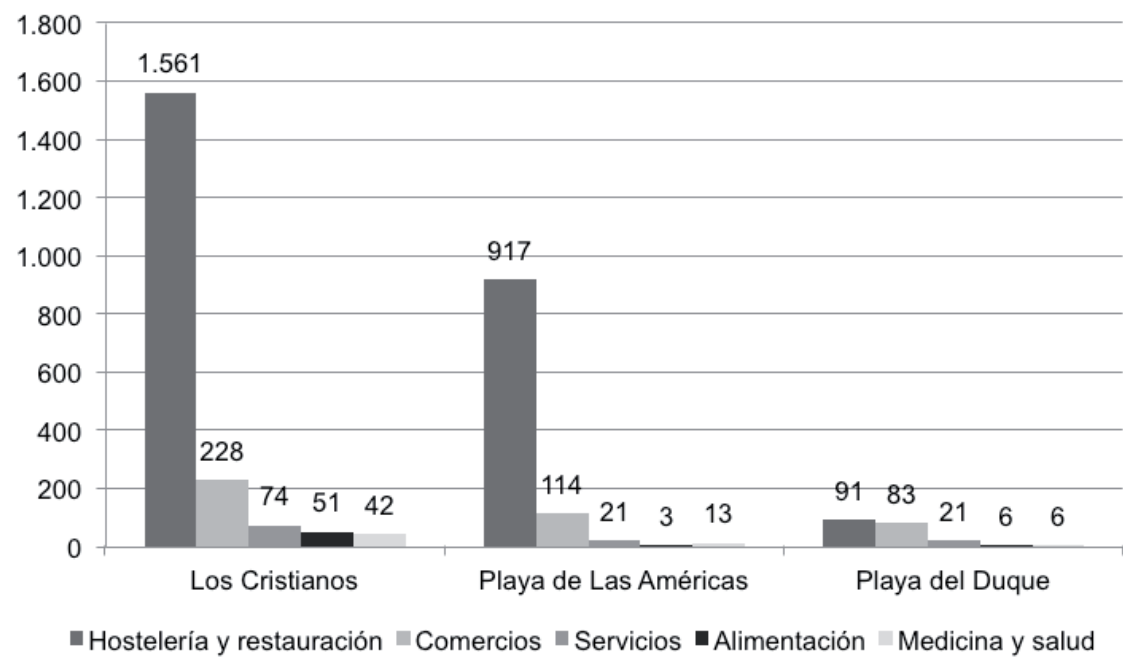

Fuente: Unidad del Banco de Datos y Centro de Documentación del Cabildo de Tenerife.

Figura 10. Segmentación territorial de la oferta comercial en los microdestinos de Bahía del Duque, Los Cristianos y Playa de Las Américas

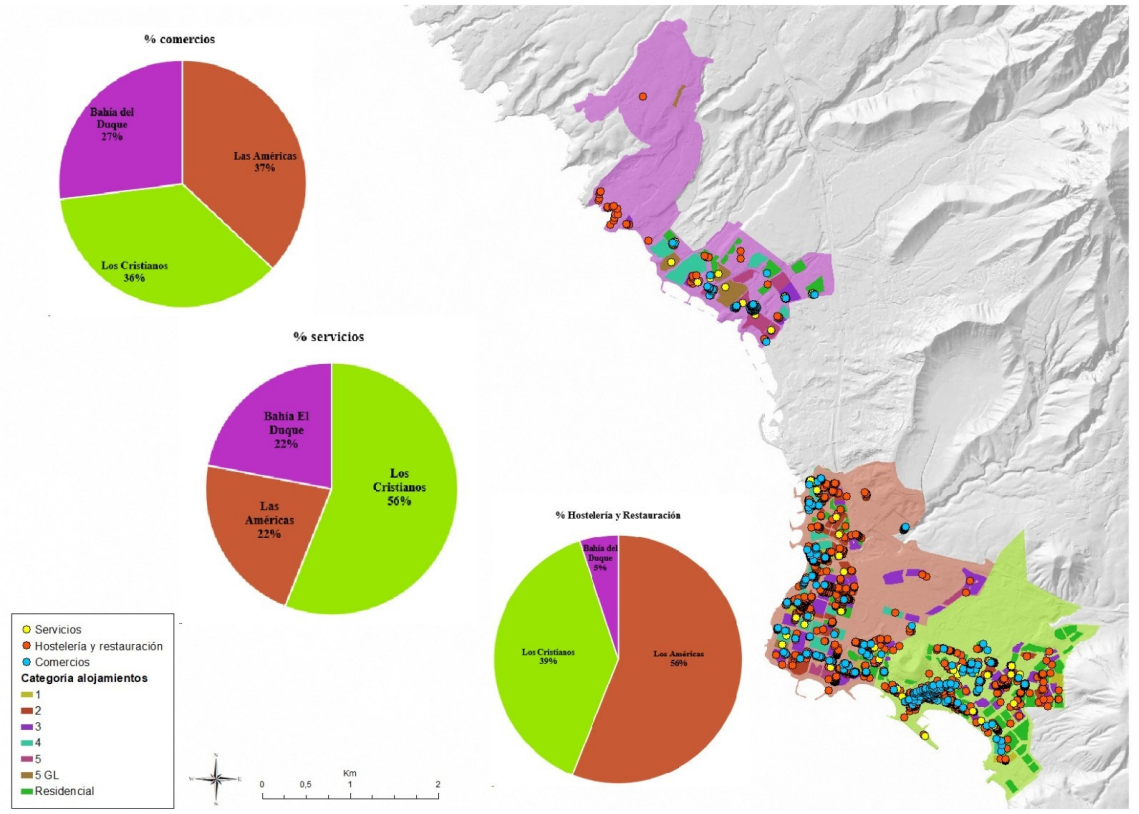

Fuente: elaboración propia. 
integrados en la morfología de la manzana cerrada y, en menor medida, en lugares en centros comerciales.

La oferta comercial en Los Cristianos se concentra significativamente en el tejido tradicional en torno al puerto y la playa. El tipo de alojamiento predominante es extrahotelero (apartamentos). Esto explica que el equipamiento comercial sea al detalle, de pequeñas dimensiones, que usa la calle como espacio de relación. Por tanto, este microdestino funciona a modo de zona comercial abierta.

La organización territorial de la oferta comercial en Las Américas es distinta. Sus patrones comerciales son de dos tipos: por un lado, la ubicación de los comercios en los locales de los establecimientos turísticos (hoteles y apartamentos), dedicados a una cesta de productos de marcas habituales; y por otro, la concentración de la oferta en centros comerciales y galerías en torno a los dos ejes vertebradores del conjunto (la avenida de Las Américas y la avenida Rafael Puig).

Por su parte, la localización de la oferta comercial en el microdestino Bahía del Duque es particular. La citada estructura alojativa determina que dicha oferta se concentre básicamente dentro de los hoteles o en centros comerciales exentos, con comercio especializado y con marcas internacionales. Lo mismo sucede con el bajo porcentaje de comercios dedicados a hostelería y restauración.

En la medida en que la localización de la oferta comercial se fundamenta en el principio de eficiencia económica y espacial (Moreno y Bosque, 2010), los patrones detectados en las tres áreas turísticas de litoral evidencian la interacción entre los alojamientos turísticos y las actividades comerciales, donde la localización, la modalidad y la cualificación de los primeros determinan la tipología de los segundos (figura 10). Esta estrategia genera una doble lógica territorial: por un lado, de distribución de los comercios en el espacio urbanoturístico en función de la modalidad y la categoría de los establecimientos de alojamiento turístico, en especial, los relativos a una amplia oferta de productos de primera necesidad y servicios a turistas y residentes; y, por otro, de polarización en determinados ámbitos y ejes significativos, en que la concentración de un tipo de alojamiento turístico articula a un tipo de comercio.

\section{Potencialidades de la segmentación territorial de la oferta comercial en las áreas turísticas de litoral}

La segmentación territorial de la oferta comercial de las áreas turísticas de litoral permite responder a innumerables preguntas de fuerte componente geográfica y que tradicionalmente han venido planteando las técnicas de marketing, debido a una serie de potencialidades.

En primer lugar, delimita las zonas de mercado de acuerdo con su potencial de rentabilidad y perfiles análogos de los turistas. De esta manera, aporta el soporte espacial adecuado para el análisis inteligente de mercados desde el punto de vista territorial. Así, por ejemplo, contribuye a medir el impacto del predominio de un tipo de alojamiento en la determinación de la oferta de acti- 
vidad comercial y económica del ámbito turístico. Esto contribuye al análisis de las economías de escala entre alojamientos turísticos próximos.

En segundo lugar, facilita la optimización de la localización y ubicación geográfica eficiente de actividades y servicios comerciales desde la reivindicación de la importancia del contexto territorial donde se ubican. Así, permite relacionar espacialmente oferta comercial y alojativa a partir de su representación en formato vectorial en un plano (puntos, líneas o polígonos) mediante relaciones topológicas. Estas últimas permiten definir y caracterizar los elementos que están juntos o más cercanos a otros, lo cual es indispensable para realizar análisis espaciales y específicamente de marketing (Burrough y McDonnel, 1998). De esta manera, contienen información importante para definir patrones de localización espacial de los equipamientos y servicios comerciales en relación con los alojamientos turísticos.

Desde este punto de vista, aporta el análisis espacial al marketing. Su aplicación al conjunto territorial de consumidores relativamente homogéneos resultante de la zonificación permite el diseño de estrategias comerciales diferenciadas para cada uno de ellos, para satisfacer de forma más efectiva sus necesidades, al orientarse hacia sus principales motivaciones. Esto resulta coherente con el planteamiento de que el mantenimiento y, sobre todo, el incremento de la competitividad de los destinos requiere su gestión como productos que, entre otras cuestiones, suponen la diferenciación en términos de relación con los lugares (Tseng et al., 2015). Así, permite una planificación comercial más efectiva no solo al posibilitar una localización óptima de los equipamientos y servicios, sino al contribuir al diseño y la implementación de estrategias diferenciadas y personalizadas.

Con relación a la primera de estas cuestiones, permite el logro de objetivos de la empresa, con el diseño y la aplicación de las acciones de marketing más eficientes para cada caso, al precisar los productos y servicios más adecuados a cada área turística en función de la tipología de la demanda, así como medir el impacto del predominio de un tipo de alojamiento en la determinación de la oferta de actividad comercial y económica del ámbito turístico.

En cuanto a la segunda, permite satisfacer eficazmente las necesidades y los deseos de cada segmento, al ser atendidos a través de estrategias específicas. Esta especialización posibilita la identificación de grupos turísticos específicos y, por tanto, una planificación de mercadotecnia más eficiente (Nickerson et al., 2016). Su importancia se incrementa, si cabe, cuando la política turística se articula en torno a la diferenciación y adaptación de la oferta de equipamientos y servicios a las demandas y expectativas del turista (consumidor), así como a la puesta en valor de una gama de productos dirigidos a segmentos de mercado concretos. Desde este punto de vista, la segmentación territorial de la oferta comercial se plantea como una referencia espacial para que las características, actitudes, comportamientos, percepciones y experiencias se adecúen a los componentes, la organización y el funcionamiento de cada espacio urbano-turístico. Esta preocupación por la orientación hacia el cliente es un planteamiento que se ha transferido al citado marketing territorial (Tseng et al., 2015). 
En tercer lugar, la segmentación territorial resultante permite identificar y predecir patrones espaciales homogéneos de comportamiento de los consumidores turísticos en relación con las actividades comerciales y aporta importantes datos estadísticos a escala microlocal, sobre todo relativos a la segmentación de la demanda. Ello deriva del hecho de que las unidades geográficas resultantes presentan indicadores estadísticos homogéneos y continuidad espacial. Asimismo, los métodos de ajuste y representación cartográfica empleados ayudan a resolver los problemas iniciales detectados en las fuentes de información utilizadas tanto cartográficas como alfanuméricas de alojamientos turísticos para posibilitar su georreferenciación con relación a la información de la oferta comercial.

Lo anterior solventa la falta de información pública espacial a escala microlocal. Los datos ad hoc generados ofrecen la posibilidad de mejorar la relevancia, la oportunidad y la puntualidad de los productos ofrecidos por fuentes oficiales puramente estadísticas. Asimismo, al introducir un tratamiento multiescalar, permiten un análisis con la suficiente desagregación escalar. Del mismo modo, hacen posible solucionar el desajuste entre la escala administrativa (de la que se dispone de datos estadísticos) y la delimitación física de las áreas turísticas. Ello resuelve la difícil correspondencia territorial que complica la cuantificación, a pesar de que la primera es la unidad estadística de mayor detalle de la que habitualmente se dispone de datos de forma masiva o sistemática. Esto supone no solo un avance respecto al cálculo de cuestiones vinculadas con los espacios turísticos — que, en cierta medida, ya podían hacerse-, sino, sobre todo, en cuanto a la posibilidad de obtener otros indicadores a escala microlocal que antes eran impensables.

La información procedimental resultante posibilita modelizar escenarios susceptibles de trazar adecuadas y consecuentes estrategias de planificación y gestión territorial de los destinos/áreas turísticas y, por tanto, la toma de decisiones. Así pues, a modo de data sciencie y business intelligence, favorece el análisis con la suficiente desagregación escalar de los datos y genera conocimiento sobre el turista y su relación con el territorio. Esto facilita la toma de decisiones inteligentes en los destinos turísticos. La inteligencia turística no es la acumulación de grandes volúmenes de datos, sino la capacidad de la transformación piramidal y secuencial de los datos (big data y open data) en información suficiente para convertirla en conocimiento, con el que abordar el proceso de toma de decisiones (Peñarrubia y Simancas, 2020).

Por último, la validación de la premisa según la cual la segmentación territorial de los alojamientos turísticos determina la organización espacial de la oferta comercial abre la posibilidad de aplicar las técnicas y estrategias de geomarketing en las unidades homogéneas resultantes. Ello hace que sea algo más que una mera técnica de geolocalización de personas a través de los datos de su ubicación geográfica obtenidos por medio de un determinado dispositivo móvil. Asimismo, se aleja del «marketing territorial» o "marketing estratégico de lugares» (Kotler et al., 1993), entendido como una estrategia para que ámbitos espaciales concretos (pueblos, ciudades, regiones o países) creen sus marcas (branding), con el fin de diferenciarlos y convertirlos en destinos competitivos (Casais y Sousa, 
2019). Por el contrario, supone un proceso de investigación de mercados y atención a los turistas articulado en torno a bases de datos con información espacial.

En definitiva, la segmentación territorial de la oferta comercial en las áreas turísticas de litoral se revela como una técnica de localización espacial óptima de equipamientos y servicios en relación con las siguientes cuestiones vinculadas al geomarketing: a) permite identificar patrones geográficos de comportamiento de los turistas - y, por tanto, la segmentación y la caracterización de la demanda en función de preferencias, gustos, intereses, motivaciones y hábitos análogos-, que facilitan el entendimiento y la predicción del comportamiento de consumo (Alcaide et al., 2012); b) posibilita la definición de los modelos de negocio más adecuados al contexto territorial donde se ubican; $c$ ) facilita la identificación del área de influencia de un determinado alojamiento, así como la delimitación de las áreas de mercado de acuerdo con su potencial de rentabilidad; d) contribuye al análisis de la competencia (procesos de "canibalización») o las economías de escala entre alojamientos turísticos y equipamientos próximos; $e$ ) permite su caracterización y tematización en función tanto de la demanda, las formas y perfiles de usuarios; $f$ ) posibilita la determinación de los índices de penetración de la oferta, para canalizar y definir el alcance y la adecuación de las campañas de promoción y publicidad del destino, y $g$ ) ayuda a definir y priorizar la ejecución de infraestructuras públicas en función de la segmentación de demanda del destino.

\section{Conclusiones}

En este trabajo se ha intentado poner de manifiesto la importancia de la dimensión geográfica en la actividad turística. Si bien los equipamientos y servicios comerciales pueden incidir en las características, prestaciones, actividades o tematización de los establecimientos de alojamientos turísticos próximos, en la mayoría de las ocasiones sucede lo contrario. Así, hemos comprobado la evidencia de los efectos de interacción entre la localización, la modalidad y la categoría de los establecimientos de alojamiento turístico y la de los equipamientos y servicios. De esta manera, los primeros constituyen uno de los factores de localización y definición de la tipología de estos últimos. Ello pone de manifiesto que la variable territorial es esencial en los procesos de segmentación, e incluso de microsegmentación, por su capacidad para identificar patrones homogéneos en cuanto a la tipología de la oferta comercial, con la consiguiente definición de unidades territoriales homogéneas.

Considerando que los establecimientos de alojamiento turístico siguen siendo los elementos que definen la estructura urbana de las áreas turísticas de litoral, la delimitación, la individualización y la singularización de unidades espaciales que comparten cierto grado de homogeneidad y especialización comercial permiten proceder a su clasificación sobre la base de determinadas regularidades y analogías relativas a las características de la oferta de alojamiento turístico. Esto posibilita la representación y la sistematización de la complejidad de los comportamientos de los consumidores turísticos a través de 
la identificación y la descomposición del área turística en zonas de propiedades comunes y regularidades. El resultado es la fragmentación territorial del espacio urbano-turístico en un amplio espectro de tipos de turistas en función de la tipología de los comercios, con necesidades o características similares, que, en cierta medida, presentan un comportamiento de compra similar. Esto supone el diseño de estrategias de marketing desde la reivindicación del territorio como eje central del análisis y la valoración del «sentido de lugar» (Campelo, 2015).

Para ello, la segmentación territorial de la oferta comercial de las áreas turísticas del litoral se plantea desde una doble perspectiva: la del entorno geográfico y la del turista. Asimismo, permite agrupar a consumidores similares dentro de un mercado no solo de acuerdo con sus necesidades, hábitos o actitudes y, por tanto, desde el punto de vista de la demanda, sino también en función de las características territoriales de las mismas y, por ende, de la oferta. Así pues, implica poner en valor la importancia existente entre la relación del alojamiento turístico y la oferta de actividades comerciales. Ello supone una reivindicación de la dimensión territorial en los procesos de toma de decisiones, públicas y privadas, por lo tanto se convierte en una técnica idónea para el conocimiento del comportamiento del turista.

\section{Referencias bibliográficas}

AlCaide, Juan; Calero, Rocío y Hernández, Raúl (2012). Geomarketing: marketing territorial para vender y fidelizar más. Madrid: ESIC Editorial.

Allo, Nicholas (2014). "A challenge for geomarketing in developing countries the Nigerian narrative». International Journal of Market Research, 56 (3), 297-316. <https://doi.org/10.2501/IJMR-2014-021a>

Amago, Fernando (2000). Logistica y marketing geográfico. Geomarketing, para tomar decisiones visualmente. Barcelona: Logis Book.

ANDERSON, Volodymyr (2004). Developing integrated object-oriented conception of Geomarketing as a tool for promotion of regional sustainable development: the case study of Ukraine. University of Idaho.

ANSELIN, Luc (1999). "The future of spatial analysis in the social sciences». Geographic Information Sciences, 5 (2), 67-76. <https://doi.org/10.1080/10824009909480516>

ANTÓN, Salvador (1998). "La urbanización turística. De la conquista del viaje a la reestructuración de la ciudad turística». Documents d'Anàlisi Geogràfica, 32, 17-43.

BARRADO, Diego (2004). «El concepto de destino turístico. Una aproximación geográfico-territorial». Estudios Turísticos, 160, 45-68.

Baviera, Amparo; Buitrago, Juan y Escribá, Carmen (2016). «Geomarketing Models in Supermarket Location Strategies». Journal of Business Economics and Management, 170 (6), 1.205-1.221. <https://doi.org/10.3846/16111699.2015.1113198>

BELTRÁN, Gersón (2014). Geomarketing: geolocalización, redes sociales y turismo. Madrid: Bubok.

Beritelli, Pietro; Bieger, Thomas y Laesser, Christian (2014). «The new frontiers of Destination management». Journal of Travel Research, 53 (4), 403-417. <https://doi.org/10.1177/0047287513506298> 
Bocalandro, Nicolás y KraUthamer, Diego (2007). «Geomarketing: aplicaciones de sistemas de información geográficos e inteligencia de negocios». Segundo Congreso Metropolitano de Ciencias Económicas. Ciudad Autónoma de Buenos Aires, $14 \mathrm{al}$ 16 de noviembre de 2007.

Burrough, Peter y McDonnel, Rachael (1998). Principles of Geographical Information Systems. Nueva York: Oxford University Press.

Butler, Richard (1991). "West Edmonton Mall as a tourist attraction». Canadian Geographer, 35, 287-295.

<https://doi.org/10.1111/j.1541-0064.1991.tb01103.x>

CAMPELO, Adriana (2015). «Rethinking sense of place: Sense of one and sense of many». En: Kavaratzis, Mihalis; Warnaby, Gary y Ashworth, Gregory J. Rethinking Place Branding. Cham: Springer International Publishing, 51-60.

CASAIS, Beatriz y SousA, Bruno (2019). «Portugal, the best destination': the case study of a CSR communication that changed mentalities and increased business performance». Review of Entrepreneurship, Management and Sust. Development, 15 (1/2), 29-41. <https://doi.org/10.1504/WREMSD.2019.10019893>

Castilhos, Rodrigo; Dolbec, Pierre y Veresiu, Ela (2014). «Conceptualizing the space of markets: How spatiality influences market dynamics». Advances in Consumer Research, 42, 265-270.

CHACON, Jorge (2017). "Geomarketing techniques to locate retail companies in regulated markets». Australasian Marketing Journal, 25, 185-193. <https://doi.org/10.1016/j.ausmj.2017.06.001>

Chancellor, Charles y Cole, Shu (2008). «Using geographic information system to visualize travel patterns and market research data». Journal of Travel y Tourism Marketing, 25 (3-4), 341-354.

<https://doi.org/10.1080/10548400802508440>

Chapman, Anya y Light, Duncan (2016). "Exploring the tourist destination as a mosaic: The alternative lifecycles of the seaside amusement arcade sector in Britain». Tourism Management, 52, 254-263. <https://doi.org/10.1016/j.tourman.2015.06.020>

CHASCO, Coro (2003). «El geomarketing y la distribución comercial». Investigación y Marketing, 79, 6-13.

Chasco, Coro y Fernández, Gema (2009). Análisis de datos espacio temporales para la economía y el geomarketing. A Coruña: NetBiblio.

Cliquet, Gérard (2006). Geomarketing. Methods and Strategies in Spatial Marketing. Londres: ISTE Ltd.

Corbera, Fernando; GonzÁlez, Rafael y VÁzQuez, Carmen (2002). «Cartografía y contenidos para aplicaciones LBS: aplicaciones de geomarketing para equipamientos públicos». En: GARCía, José; Molina, Ignacio y López, Gonzalo Andrés (coord.). Ciencia y tecnología de la información geográfica en un mundo globalizado. X Congreso del Grupo de Métodos Cuantitativos, Sistemas de Información Geográfica y Teledetección, 15. Valladolid, 17-20 de septiembre.

DELGADO, Joaquín (2010). "Presente y futuro de las relaciones de colaboración entre el registro de la propiedad y el catastro. La identificación geográfica de las fincas registrales y la interoperabilidad entre cartografías». I Congreso Internacional sobre Catastro Unificado Multipropósito. Universidad de Jaén, 16 a 18 de junio.

DouARD, Jean y HeITZ, Michèle (2004). Le Geómarketing: Au service de la démarche Marketing. París: Dunod. 
Doyle, Shaun (2001). «Software Review: How Is Geography Supporting Marketing in Today's Commercial Organizations?». Journal of Database Marketing, 9 (1), 85-89.

DredGE, Dianne (1999). «Destination place planning and design». Annals of Tourism Research, 26 (4), 772-791.

EsCobAR, Nelcy; JÁCOME, Javier y GARCíA, Giselle (2015). «El geomarketing como instrumento para la toma de decisiones de mercado en la organización: una caracterización preliminar de su utilidad». Espacios, 36 (18), 8.

Ferreira, Sergio (2011). "Geo-segmentación y geo-posicionamiento en el análisis de las preferencias de los turistas: la geometría al servicio del marketing». Estudios y Perspectivas en Turismo, 20, 842-854.

GALACHO, Federico (1999). «Diseño conceptual y posibilidades de aplicación a la planificación estratégica de la empresa turística de un sistema de información geográfica». TuriTec'99: I Congreso Nacional Turismo y Tecnologías de la Información $y$ las Comunicaciones, 35-47.

GARCÍA, Juan (1996). «Geomarketing. Los sistemas de información geográfica aplicados a la planificación comercial». Distribución y Consumo, 31, 99-107.

García, Juan; Simancas, M. y DOrTA, A. (2013). «La utilización de las bases gráficas del Registro de la Propiedad y del Catastro en la elaboración de un Sistema de Información Geográfica sobre la oferta de alojamiento turístico de Canarias». En: SÁNCHEZ, Elena (dir.). El impacto de las nuevas tecnologías en la publicidad registral. Monografía asociada a la Revista Aranzadi de Derecho y Nuevas Tecnologías, 11. Navarra: Editorial Aranzadi, 313-329.

GrimmEAU, Jean y RoELANTS, Machteld (1995). «Géomarketing: une présentation a travers huit ans de pratique». Revue Belge de Géographie, 119, 289-306.

HARRIS, Richard (2003). "An introduction to mapping the 2001 Census of England and Wales». Society of Cartographers Bulletin, 37, 39-42.

Hernández, R.; Simancas, M.; GonZÁlez, A.; RodrígueZ, Y.; García, J. I. y GonZÁLEZ, Y. (2016). «Identifying micro-destinations and providing statistical information: a pilot study in the Canary Islands». Current Issues in Tourism, 19 (8), $771-790$ <https://doi.org/10.1080/13683500.2014.916657>

HeUnG, Vincent y CHENG, Eliza (2000). «Accessing tourists' satisfaction with shopping in the Hong Kong special administrative region of China». Journal of Travel Research, 38 (4), 396-404. <https://doi.org/10.1177/004728750003800408>

Instituto CANARIO DE Estadística (2015). Infraestructura Estadistica. Entidades y núcleos turísticos. Cuaderno cartográfico. Santa Cruz de Tenerife: ISTAC.

International Network on Regional Economics, Mobility and Tourism y United Nations World Tourism Organization (2012). A closer look at tourism: Sub-national measurement and analysis - towards a set of UNWTO guidelines. Madrid: UNWTO.

IVARS, Josep; SOlSONA, Francisco y GINER, David (2016). "Gestión turística y tecnologías de la información y la comunicación (TIC): el nuevo enfoque de los destinos inteligentes». Documents d'Anàlisi Geogràfica, 62 (2), 327-346. <http://dx.doi.org/10.5565/rev/dag.285>

JANSEN, Myriam (1991). «Leisure shopping: a magic concept for the tourism industry?». Tourism Management, 12 (1), 9-14. $<$ https://doi.org/10.1016/0261-5177(91)90024-N> 
Jin, Haipeng; MOSCARDO, Gianna y MURPHY, Laurie (2017). «Making sense of tourist shopping research: A critical review». Tourism Management, 62, 120-134. <https://doi.org/10.1016/j.tourman.2017.03.027>

Kim, Soyoung y LiTTRell, Mary (2001). «Souvenir buying and intentions for self versus others". Annals of Tourism Research, 28 (3), 638-657. <https://doi.org/10.1016/S0160-7383(00)00064-5>

Kotler, Philip; HaIDER, Donald y ReIn, Irving (1993). Marketing places: attracting investment, industry, and tourism to cities, states, and nations. Nueva York: The Free Press.

LATOUR, Philippe y LE FlOCH, Jacques (2001). Géomarketing: principes, méthodes et applications. París: Éditions d'Organisation.

LAW, Rob y Au, Norman (2000). "Relationship modelling in tourism shopping: a decision rules induction approach». Tourism Management, 21 (3), 241-249. <https://doi.org/10.1016/S0261-5177(99)00056-4>

LeE, Kyung; Kang, Sanghoon; Terry, William y SchuetT, Michael (2018). «A spatial relationship between the distribution patterns of hotels and amenities in the United States». Cogent Social Sciences, 4, 1. <https://doi.org/10.1080/23311886.2018.1444918>

Lehto, Xinran; CHen, Sabrina y SilKes, Carol (2014). «Tourist shopping style preferences». Journal of Vacation Marketing, 20, 15-23. <https://doi.org/10.1177/1356766713484727>

LEW, A. y MCKercher, B. (2006). "Modeling tourist movements: A local destination analysis». Annals of Tourism Research, 33 (2), 403-423. <https://doi.org/10.1016/j.annals.2005.12.002>

Magadán, Marta y Rivas, Jesús (2014). Turismo de shopping. Oviedo: Septem Ediciones.

Meng, Fang y Xu, Yingjiao (2012). «Tourism shopping behavior: Planned, impulsive, or experiential?». International Journal of Culture, Tourism and Hospitality Research, 6 (3), 250-265. <https://doi.org/10.1108/17506181211246401>

MONTEJANO, Jorge y CRUZ, Gustavo (2018). «Modelos de localización para geomarketing». Espacialidades. Revista de Temas Contemporáneos sobre Lugares, Política y Cultura, 8 (1).

Moreno, Antonio (2001). Geomarketing con sistemas de información geográfica. Madrid: Asociación de Geógrafos Españoles.

- (2002). «Delimitación y predicción del área de mercado para establecimientos de servicios a los consumidores con sistemas de información geográfica». Estudios Geográficos, 247, 279-302. <https://doi.org/10.3989/egeogr.2002.i247.253>

- (2012). «Modelos de localización óptima de instalaciones y equipamientos». En: BOSQUE, Joaquín y MORENO, Antonio (eds.). Sistemas de información geográfica y localización óptima de instalaciones y equipamientos. México: AlfaOmega / Ra-Ma, 73-122.

Moreno, Antonio y Prieto, María (2004). "¿Cómo afecta la unidad espacial a la visualización y modelado del área de mercado con sistemas de información geográfica? Implicaciones para el geomarketing». Estudios Geográficos, 65 (257), 617-636. <https://doi.org/10.3989/egeogr.2004.i257.169>

Moreno, Antonio y Bosque, Joaquín (2010). «Los modelos de localización óptima como herramientas para la planificación territorial y urbana de instalaciones y equipamientos». Estudios Territoriales, 165, 461-480. 
Moscardo, Gianna (2004). «Shopping as a Destination attraction: an empirical examination of the role of shopping in tourists' Destination choice and experience». Journal of Vacation Marketing, 10 (4), 294-307. <https://doi.org/10.1177/135676670401000402>

Mullins, Patrick (1991). «Tourism Urbanization». International Journal of Urban and Regional Research, 15 (3), 326-342. <https://doi.org/10.1111/j.1468-2427.1991.tb00642.x>

NiCKerSON, N.; JORGENSON, J. y BOLEY, B. (2016). «Are sustainable tourists a higher spending market?». Tourism Management, 54, 170-177. <https://doi.org/10.1016/j.tourman.2015.11.009>

OPPERMANN, Martín (1997). "Geography's changing role in tourism marketing». Journal of Travel \& Tourism Marketing, 6 (3-4), 1-3. <https://doi.org/10.1300/J073v06n03_01>

Papatheodorou, Andreas (2006). "Microfoundations of tourism choice». En: DWYER, Larry y FORSYTH, Peter (ed.). International handbook on the economics of tourism. Cheltenham: Edward Elgar, 73-88.

Park, Kwang; Reisinger, Yvette y NoH, Eun (2009). "Luxury shopping in tourism». International Journal of Tourism Research, 12, 164-78. $<$ https://doi.org/10.1002/jtr.744>

PELECHÁ, Ana (2011). Turismo de shopping: El turismo de shopping como nueva tipología de turismo. Valencia: Universitat de València.

PeÑARrubia, María-Pilar (2018). Los datos estadisticos públicos y su uso en el conocimiento del comportamiento de los turistas en destinos inteligentes. Tesis doctoral. Valencia: Universitat de València.

Peñarrubia, María-Pilar; Simancas, Moisés y Forgione, Geraldine (2019). «Application of geomarketing to coastal tourist areas». Tourism y Management Studies, 15 (4), 7-20. <https://doi.org/10.18089/tms.2019.150401>

Peñarrubia, María-Pilar y SimanCAS, Moisés (2020). «Análisis multiescalar de las fuentes estadísticas públicas de turismo». En: SimanCAS, Moisés y PeŃARrubia, María-Pilar (coord.). El valor de los datos turísticos. Valencia: Editorial Tirant lo Blanch / Cátedra de Turismo Caja Canarias - Ashotel de la Universidad de La Laguna, 183-212.

REISINGER, Yvette y TURner, Lindsay (2002). "The determination of shopping satisfaction of Japanese tourists visiting Hawaii and the Gold Coast compared». Journal of Travel Research, 41 (2), 167-176. <https://doi.org/10.1177/004728702237417>

Rodríguez, Vicente; Olarte, Cristina y SaCo, Manuela (2016). «Aplicación de geomarketing en la optimización de una red de puntos de venta». Cátedra Fundación Ramón Areces de Distribución Comercial (DOCFRADIS), 1.602, 1-21.

RodrígueZ, Yurena y HERnÁNDEZ, Raúl (2018). «Foundations and relevance of delimiting local tourism destinations». Journal of Regional Research, 42, 185-206.

Rosenbaum, Mark y SPEARS, Daniel (2009). "Using group comparisons in AMOS to explore shopping as a travel driver». International Journal of Culture, Tourism and Hospitality Research, 3 (4), 313-325.

SousA, Bruno; Malheiro, Alexandra Cláudia y Veloso, Miranda (2019). "O Marketing Territorial como Contributo para a Segmentação Turística: Modelo conceptual no turismo de shopping». International Journal of Marketing, Communication and New Media, 5, 93-116. 
Sundström, Malin; Lundberg, Christine y GiannaKis, Stavroula (2011). «Tourist shopping motivation: Go with the flow or follow the plan». International Journal of Quality and Service Sciences, 3 (2), 211-224. <https://doi.org/10.1108/17566691111146104>

SwANSON, Kristen y HORRIDGE, Patricia (2006). «Travel motivations as souvenir purchase indicators». Tourism Management, 27, 671-683. <https://doi.org/10.1016/j.tourman.2005.03.001>

TiмотHY, Dallen (2005). Shopping Tourism, Retailing and Leisure. Nueva York: Channel View Publications.

Tosun, Cevat; Temizkan, Saadet; Timothy, Dallen y Fyall, Alan (2007). «Tourist Shopping Experiences and Satisfaction». International Journal of Tourism Research, 9, 87-102. <https://doi.org/10.1002/jtr.595>

Tseng, Chi; Wu, Bihu; Morrison, Alastair; Zhang, Jingru; Chen, Ying-chen (2015). "Travel blogs on China as a destination image formation agent: A qualitative analysis using Leximancer». Tourism Management, 46, 347-358. <https://doi.org/10.1016/j.tourman.2014.07.012>

Turner, Lindsay y ReIsinger, Yvette (2001). "Shopping satisfaction for domestic tourists». Journal of Retailing and Consumer Services, 8, 15-27. <https://doi.org/10.1016/S0969-6989(00)00005-9>

United Nations World Tourism Organization (2007). A practical guide to tourism destination management. Madrid: UNWTO.

VALLEJO, Ismael y MÁRQUEZ, Joaquín (2006). «SIGCOMSE: un sistema de información geográfica aplicado al comercio en la ciudad de Sevilla». GeoFocus (Informes y comentarios), 6, 28-38.

WAGNER, Tillmann (2007). «Shopping motivation revised: a means-end chain analytical perspective». International Journal of Retail y Distribution Management, 35 (7), 569-582.

World Tourism Organization (2014). AM Reports, Volume Eight, Global Report on Shopping Tourism. Madrid: UNWTO. 